\title{
Strategies for reducing visual impairment and blindness in rural and remote areas of Africa
}

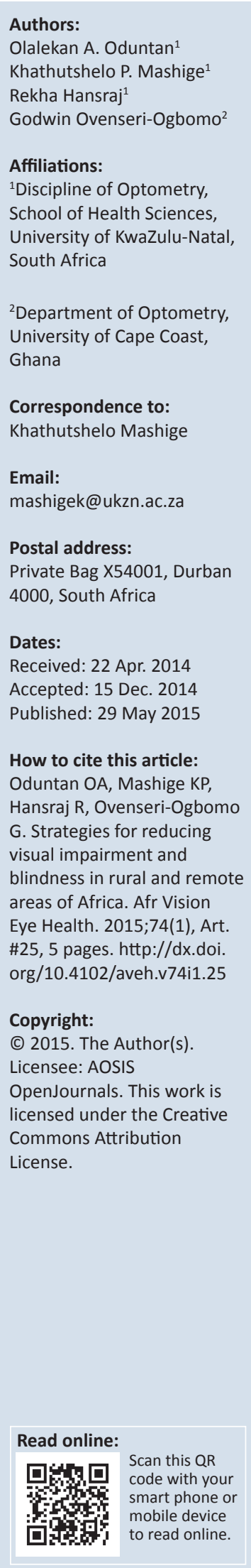

The prevalence of visual impairment (VI) and blindness in Africa is one of the highest in the world; a large proportion of the causes are preventable. The prevalence is particularly high in rural and remote areas, where many of the continent's inhabitants live. This is of great concern because of the low number and poor distribution of primary eye care practitioners, as well as poor eye care infrastructure services in those areas. Uncorrected refractive errors are a major cause of avoidable VI and blindness, and optometrists play a major role in refractive error correction on the continent. However, as with other healthcare providers in Africa, optometrists are few and tend to be mainly in major cities. This paper highlights possible strategies, in alignment with the Ottawa Charter for Health Promotion, that can reduce VI in rural and remote areas of the continent. The strategies include increasing the eye care workforce, attracting them to rural areas and retaining them there, improving the eye care infrastructure, service improvement such as equitable distribution of eye care practitioners, implementing preventive measures such as vision screening and affordable spectacles, and eye health education such as eye health promotions, school health programmes and eye care awareness campaigns. Such strategies could drastically reduce the prevalence of VI and blindness in rural and remote areas of Africa.

\section{Introduction}

Good health is a major resource for social, economic and personal development and an important dimension of quality of life ${ }^{1}$; healthcare services should therefore be provided for every citizen. Health promotion focuses on achieving equity in health by reducing differences in current health status and ensuring equal opportunities and resources to enable all people to achieve their fullest health potential. ${ }^{1}$ Health promotion demands coordinated action by all concerned: government, health and other social and economic sectors, non-governmental and voluntary organisations, industry, the media, families and communities. ${ }^{1}$ Globally, many people live in rural areas where they experience poor health as a result, in part, of limited access to health services. ${ }^{2,3}$ In many countries, this limited access to health services in rural areas is the result of considerable imbalances between urban and rural health care services, and manifests in a number of ways; these include rural areas having limited availability of healthcare personnel, lack of social infrastructure (including electricity, water, access to information and communication technology), limited opportunities for professional development, and poor prospects for lucrative part-time private practice for health workers. ${ }^{4,5,6}$ Healthcare, including eye care provision, is a right of every member of society; therefore people living in rural and remote areas should receive similar levels of eye care to those living in urban areas.

In many developing nations, including those in Africa, the eye care sector is one of the healthcare areas most affected by the maldistribution of personnel and services. A scarcity of eye care services has been reported in many rural areas $5,6,7,8,9,10,11$ and more so in Africa, where the limited number of health workers is compounded by the so-called brain drain ${ }^{12,13}$ of qualified healthcare personnel emigrating to developed countries. As is the case in many developed and developing nations globally, eye care services in Africa are provided mainly by optometrists and ophthalmologists. ${ }^{14}$ Other cadres of eye care providers include ophthalmic nurses, ophthalmic medical officers, refractionists, etc. Optometrists are primary eye care practitioners, and therefore are key in providing eye care services in rural and remote areas of Africa. Optometrists offer services such as refractive error correction by the provision of spectacle lenses and contact lenses, paediatric vision management, binocular vision anomaly management, low vision rehabilitation, and ocular disease diagnoses and management. ${ }^{15}$ In a few African countries, such as Ghana, Nigeria, ${ }^{16}$ South Africa and Sudan, the use of diagnostic drugs is permissible. ${ }^{17}$ Furthermore, limited prescription of therapeutic drugs to manage anterior segment diseases is permitted in Ghana, Nigeria ${ }^{17}$ and, in some circumstances, in South Africa. 
Optometry is not yet fully recognised as a healthcare profession in many African countries, with eye care services being provided by refractionists or nurses. ${ }^{17}$ In countries with no optometrists, refractionists are trained to provide limited services such as determination of spectacle prescription. However, optometrists would be preferrable as they can perform several eye care services other than only refraction. Optometry has been recognised as a healthcare profession mainly in those countries with schools of optometry and strong optometric associations; for example, in South Africa, Nigeria and Ghana. ${ }^{17}$ Optometry has also thrived as a legislated primary healthcare profession in Tanzania, Sudan and Ethiopia. ${ }^{18}$ In countries with optometrists, ophthalmologists often concentrate on secondary and tertiary services, such as medical and surgical eye care services. But because of the absence of adequate services and the lack of social and health care infrastructure in rural and remote areas of Africa, people who need access to preventive and curative eye care services are unable to access or afford them.

The principal cause of visual impairment (VI) all over the world is uncorrected refractive error ${ }^{19,20}$ which is reported to be the most common cause of treatable blindness in many parts of Africa. ${ }^{21,22}$. For example, in a rural health district of Cameroon, Oye et al. ${ }^{21}$ found that refractive errors were an important cause of severe visual impairment (15\%) and moderate visual impairment (22.5\%). Among Nigerians 40 years and older, refractive errors have been reported to be the cause of $77.9 \%$ cases of mild VI, $57.1 \%$ of moderate VI, $11.3 \%$ of severe VI and $1.4 \%$ of blindness. ${ }^{22}$ The need for refractive correction is high in rural and remote areas of many regions of the world and is exacerbated by the lack of eye care services. Unfortunately, the ratio of optometrists to population in those areas is very high, with Holden and Resnikoff ${ }^{23}$ estimating it to be 1:600 000 in some developing countries. It is possible that this ratio may be true for many rural and remote areas in Africa. The optometric workforce therefore needs to be expanded, and retained, in rural and remote areas if the burden of VI and blindness in Africa is to be reduced.

The World Health Organization (WHO) and partners have developed a global initiative to eliminate avoidable blindness by the year $2020,{ }^{24}$ with one of the major foci being refractive error correction. A number of non-governmental organisations (NGOs) and schools of optometry are engaged in providing primary eye care services in many parts of Africa, including refractive correction in rural areas. ${ }^{25}$ The refractive error services provided by these NGOs are sometimes not sustainable in the long term; this is because, without the local workforce to continue these services, the services soon become unavailable when NGO projects are concluded. Therefore, there is a need for training more optometrists and other cadres of eye care providers to meet the refractive error correction needs of rural communities. This is particularly recommended for the majority of African countries where there are at present no such schools. The current high prevalence of visual impairment in rural and remote areas of Africa needs an intervention. Professionals, social groups and health personnel have a major responsibility to mediate between differing interests in society regarding the pursuit of health. ${ }^{1}$ It is in the light of this responsibility that the present article was written to suggest strategies for the reduction of VI and blindness in Africa. The suggestions include increasing eye care manpower, infrastructure development and improving service delivery.

\section{Manpower development}

Poor availability and accessibility are important factors that create barriers to eye care utilisation and manpower development is key in addressing these barriers. There is a need to increase eye care manpower in Africa to address the high level of VI and blindness, by increasing the number of optometrists, ophthalmic nurses and ophthalmologists.

Africa, with 54 countries and a population exceeding a billion, has only seven countries with institutions offering optometry training; ${ }^{18}$ and those countries have far fewer schools of optometry per capita than other developed and developing countries (Table 1). Consequently, the continent urgently needs more departments or schools of optometry. Ways to increase the optometric workforce include establishing optometry schools in those countries where there are no tertiary academic institutions providing such education, and increasing student intakes into the existing institutions. These steps would have important implications for infrastructure and academic staff, requiring governments to commit themselves to provide funds for their establishment and maintenance. In addition, where possible, existing institutions need to increase their postgraduate intakes to meet the staff training needs of current and emerging institutions.

Ophthalmic nurses are an important segment of the eye healthcare practitioners needed in rural and remote areas of Africa, if VI and blindness are to be reduced. As ophthalmologists tend not to work in rural and remote areas, ophthalmic nurses will be needed to work in conjunction with optometrists to reduce VI and blindness. Ophthalmic nurses who are certified to treat minor eye injuries and

TABLE 1: Selected countries and their estimated population, number of optometry schools, number of optometrists in the country, and optometrist:population ratio.

\begin{tabular}{lllll}
\hline Country & $\begin{array}{l}\text { Population }^{26} \\
\text { (millions) }\end{array}$ & $\begin{array}{l}\text { Optometry } \\
\text { schools }^{24,25}\end{array}$ & Optometrists & $\begin{array}{l}\text { Optometrist: } \\
\text { population ratio }\end{array}$ \\
\hline America & 314 & 21 & 35000 & $1: 9000$ \\
Australia & 22 & 5 & 4000 & $1: 5500$ \\
Canada & 34 & 2 & 5000 & $1: 6800$ \\
Malaysia & 29 & 7 & 700 & $1: 41000$ \\
India & 1220 & 49 & 44000 & $1: 27000000$ \\
Ethiopia & 91 & 1 & 54 & $1: 168000$ \\
Ghana & 20 & 2 & 250 & $1: 80000$ \\
Mozambique & 24 & 1 & 18 & $1: 133000$ \\
Nigeria & 170 & 5 & 2400 & $1: 71000$ \\
South Africa & 53 & 4 & 3400 & $1: 15600$ \\
Sudan & 34 & 1 & 500 & $1: 68000$ \\
\hline
\end{tabular}


diseases should be able to manage minor ophthalmic complaints such as conjunctivitis and eye injuries that, if not managed promptly, can lead to low vision and blindness. Leucona ${ }^{27}$ estimated that there were only 65 ophthalmic nurses in the South African public sector, which serves $80 \%$ of the population, and the number of this category of eye care workers may be lower in other African countries. According to the Global Human Resource Development Assessment for Comprehensive Eye Care, ${ }^{14} 17$ (37\%) out of 40 countries surveyed were considered to be at a stage of 'red alert', having one ophthalmic-allied professional (including ophthalmic nurses) per 200000 population or more, which compares unfavourably with the ratio of 1:100 000 population necessary to meet the goal of Vision 2020. The number of ophthalmic nurses working in the public sector throughout Africa needs to be researched and, if found to be low in any country, governments should be advised to increase efforts and strategies to increase the number. There is a need for ophthalmic nurses to work with optometrists in rural areas to enhance service provision in preventing VI. Such joint services are currently provided in Limpopo Province of South Africa to reduce VI in the rural areas. ${ }^{28}$

The ophthalmologist/population ratio in Africa is considered to be low. The number of ophthalmologists in South Africa, for example, is relatively small and they practice mainly in the major cities. ${ }^{29}$ Similar situations have been reported in other African countries. ${ }^{30,31}$ Moreover, some of the available ophthalmologists often manage ocular conditions that could be handled by primary eye care providers such as optometrists and ophthalmic nurses. The implication of this practice is that there is an additional pressure on the available ophthalmologic workforce in their capacity to deal with major surgical cases. This situation obviously affects eye care services and needs to be addressed by the relevant educational and health authorities throughout the continent. Whilst ophthalmologists may not be needed in rural and remote areas if optometric and ophthalmic nursing services are implemented, the need to increase the number of ophthalmologists in public service remains, owing to the anticipated increase in the number of patients with serious eye and vision problems who would be referred by those providing primary healthcare services. If referrals are made and there are no ophthalmologists to attend to the more serious and complicated cases, VI and blindness will not be reduced. Hence, in addition to ensuring an appropriate referral system amongst the various cadres of primary eye care workers, there is a need to train more ophthalmologists, especially in the subspecialty areas; this could be achieved if governments increase healthcare budgets to fund more ophthalmology positions in tertiary institutions and hospitals.

\section{Infrastructure development}

One of the main barriers to healthcare services, especially in rural and remote areas of Africa, is the absence or limited availability of social and healthcare infrastructure. Addressing this limitation needs to be part of the solutions for reducing VI and blindness in those areas. As most governmental and private eye care services on the continent are located in urban areas, and much of the rural population are of low socio-economic status, health and social infrastructure are important components of preventative eye healthcare. Thivhafuni ${ }^{32}$ found poor availability, accessibility and affordability of optometry services in the rural areas of Mutale Municipality, in Limpopo Province, South Africa, and recommended that eye care infrastructure be developed as part of the existing health facilities or specifically for eye care services, which might be in the form of eye clinics where optometrists would provide refractive error correction services and diagnoses of eye and ocular manifestations of systemic diseases. Also, ophthalmic nurses could provide medication for minor eye diseases to manage minor eye injures; and serious eye problems could be referred from the centres to ophthalmologists in urban areas. Non-availability of such eye care centres in rural and remote areas means that eye conditions that might be easily diagnosed and managed could result in VI and blindness.

Many health workers do not wish to work in rural areas because of factors such as poor infrastructure and lack of security ${ }^{33}$; thus indirectly creating a barrier to equitable manpower distribution. To address this issue, we suggest that more optometrists and ophthalmic nurses be employed by governments and be deployed to rural and remote areas. Efforts need to be made to attract and retain them in those areas, by providing appropriate infrastructure as well as comfortable and secure environments. Infrastructure could include salubrious housing for practitioners and schools for their children, as well as recreational facilities, to encourage health workers to reside in those areas. Electricity should be available, and access to information and telecommunications be provided, as part of the incentives to attract eye care workers to rural and remote areas. Also, financial incentives such as rural allowances may need to be paid to eye care workers. As the provision of these infrastructural facilities has serious financial implications, governments must commit themselves to making the necessary funds available if VI and blindness are to be reduced in Africa. Governments need to look into strategies such as increasing healthcare or other budgets to provide these infrastructural needs.

\section{Service improvement}

Service improvement that includes provision of affordable or free spectacles and eye drops, vision screening and awareness campaigns will need to be provided as part of the effort to reduce VI and blindness in rural and remote areas. Spectacles and basic eye drugs are not readily available in many rural and remote areas of Africa, and the inhabitants may not have easy access to major cities or towns where medication can be obtained; transport is a major problem for those with prescriptions for refractive error correction or minor eye diseases. In certain cases, the cost of transportation alone may be a barrier to purchasing prescribed spectacles or medicines. ${ }^{34}$ Naidoo et al. ${ }^{34}$ suggested that affordability of eye care needs to be looked at in a broader context; for example, 
the cost of travelling to a clinic needs to be factored into the overall cost of obtaining spectacles. Therefore, African governments need to consider providing eye care services, and affordable spectacles and drugs, at primary healthcare facilities in rural areas. It is necessary to acknowledge the efforts of several local and international NGOs, many of which currently provide eye care services and supply spectacles free of charge to people living in rural areas of Africa. These efforts need to be complemented by African governments to ensure greater availability of the services needed by the people whom they are meant to serve. Government might need to partner with NGOs and optometry institutions by providing funds for ophthalmic appliances and medications specifically for citizens living in rural and remote areas.

Vision screening and school health programmes could be utilised as possible strategies for reducing VI and blindness in rural areas. Jose and Sachdeva ${ }^{35}$ advocated the use of eye screening at schools as a strategy to meet the challenge of reaching communities in under- or unserved areas in the national programme for the control of blindness in India. School health policy in South Africa ${ }^{36}$ includes the provision of vision screening, amongst other services. We recommend that other African countries implement vision screening in rural and remote areas in an effort to reduce VI and blindness.

Appropriate and adequate use of eye care services is a key factor in reducing the burden of VI in any community, ${ }^{37}$ and an important step is to address the barriers preventing the rural population from accessing and utilising such services. The three main factors that contribute to the high prevalence of VI, particularly in rural and remote areas, are non-availability, non-accessibility and non-affordability of eye care services. ${ }^{38}$ However, even when services are available, accessible and affordable, there are other barriers that might prevent people from using them. These obstacles include lack of knowledge about the services, where to seek eye care, the possible effects of an eye disease, and whom to consult to manage eye diseases..$^{39,40}$ Social attitudes and cultural beliefs may also act as barriers to using available services. $^{41,42}$ For example, people in rural areas associate wearing glasses with impending blindness, and therefore do not always easily accept wearing spectacles. ${ }^{28}$ These factors perhaps indicate the need for another cadre of eye care personnel (primary eye health promotion workers) who could provide counselling, educational and awareness campaigns about eye care services to those living in rural and remote areas. An eye health promotion course might be a two-year diploma programme with emphasis on eye health promotion (vision screening, counselling, awareness campaign and referral). The curriculum for the course should include how to educate rural residents on ocular hygiene; basic knowledge of common eye diseases and how they affect vision; and types of eye care services, such as refractive correction, medication and surgery, and where they can be accessed. Training on societal and cultural beliefs that act as barriers to eye care utilisation should be part of the curriculum. The content of the course should include aspects of social work, psychology, counselling, diagnosis of eye conditions and referral methods. Creating this cadre of rural health workers is in line with recommendation of the WHO for rural health workers. ${ }^{4}$ Training of these workers would take place in existing optometry departments, with input from the psychology, social work and occupational therapy departments. Such an initiative will require advocacy at government level and support from relevant policymakers such as health professions councils, boards of optometry and/or similar bodies.

\section{Conclusion}

Refractive errors are major causes of VI and blindness in Africa. Unfortunately, there are insufficient optometrists to provide the required refractive services, especially in rural and remote areas. There is a need to train more optometrists, with curricula emphasising rural eye care. Also, if necessary, more ophthalmic nurses need to be trained to meet rural community needs, and they need to be attracted to, and retained in, rural areas, therefore the necessary infrastructure, a secure environment and financial incentives need to be provided. Furthermore, if necessary, more ophthalmologists need to be trained to meet increased referrals from rural areas. For effective eye health promotion in rural areas, another cadre of eye care professionals (eye health promotion workers) is perhaps needed. Also, governments need to ensure that eye care services are affordable to people living in rural and remote communities, which can be accomplished via governmental spectacle and drug subsidy schemes. The strategies discussed in this article would enhance availability, accessibility and affordability of eye care services for primary care such as refractive error correction and management of minor eye diseases and injuries, which would in turn reduce the prevalence of VI and blindness. These issues concern all those who are interested in the reduction of VI and blindness in Africa.

\section{Acknowledgement Competing interests}

The authors declare that they have no financial or personal relationships which may have inappropriately influenced them in writing this article.

\section{Authors' contributions}

All authors contributed to the conceptualisation and writing of this article.

\section{References}

1. Ottawa Charter for Health Promotion. [cited 17 November 2014]. Available from http://www.who.int/healthpromotion/conferences/previous/Ottawa/en

2. Rabinowitz HK, Diamond JJ, Markham FW, Wortman JR. Medical school programs to increase the rural physician supply: A systematic review and projected impact of widespread replication. Acad Med. 2008;83:235-243. http://dx.doi.org/10.1097/ ACM.0b013e318163789b

3. Wilson NW, Couper ID, De Vries E, Reid S, Fish T, Marais BJ. A critical review of interventions to redress the inequitable distribution of healthcare professionals to rural and remote areas. Rur Rem Health. 2009;9:1060-1069. 
4. World Health Organization. Increasing access to health workers in remote and rural areas through improved retention: Global recommendations. Geneva: World Health Organization; 2010. [cited 22 February 2013]. Available from: http:// whqlibdoc.who.int/publications/2010/9789241564014_eng.pdf

5. Eze BI, Maduka-Okafor. An assessment of eye care workforce in Enugu State, southeastern Nigeria. Hum Res Health. 2009;7:38-43. http://dx.doi.org/10.1186/14784491-7-38

6. Odusote K. People deliver eye care: Managing human resources. Comm Eye Health. 2006;18:117-119.

7. Oduntan AO, Nthangeni, ME, Ramudzuli MR, Madu SN. Causes and prevalence of low vision and blindness in black South African adults in the Limpopo province. S Afr Optom. 2003;62:8-15.

8. Mashige KP, Naidoo KS. Optometric practices and practitioners in KwaZulu-Natal, South Africa. S Afr Optom. 2010;69:77-85.

9. Fafowora OF. Prevalence of blindness in rural ophthalmically underserved Nigerian community. West Afr Med J. 1996;15:228-231.

10. Ashaye A, Ajuwon A, Adeoti C. Perceptions of blindness and blinding conditions in rural communities. J Nat Med Assoc. 2006;98:887-893.

11. Chandrashekar TS, Bhat HV, Pai RV, Nair SK. Coverage, utilization and barriers to cataract surgical services in rural South India: Results from a population based study. Public Health. 2007;121:130-136. http://dx.doi.org/10.1016/j. puhe.2006.07.027

12. Labonte $\mathrm{R}$, Packer $\mathrm{C}$, Klassen $\mathrm{N}$, et al. The brain drain of health professionals from sub-saharan Africa to Canada. Ontario: Southern African Migration Project; 2006.

13. Chikanda A. Skilled health professionals' migration and its impact on health delivery in Zimbabwe. Oxford: University of Oxford; 2004.

14. Pakistan Institute of Community Ophthalmology. Global human resource development assessment for comprehensive eye care. Karachi: International Agency for the Prevention of Blindness; 2006.

15. Smith DP. The 75th anniversary of the World Council of Optometry. Clin Exp Optom. 2002; 85:210-213. http://dx.doi.org/10.1111/j.1444-0938.2002.tb03039.x

16. Federal Republic of Nigeria. Optometrists and dispensing opticians (registration) Act 34. Lagos: Federal Republic of Nigeria; 1989.

17. Padilla MA, Di Stefano AF. A snapshot of optometry around the world. Rev Optom 2009;15:55-57.

18. Oduntan OA, Mashige KP, Kio F, Boadi-Kusi SB. Optometric education in Africa: Historical perspectives and challenges. Optom Vis Sci. 2014;91:359-365.

19. Resnikoff S, Pascolini D, Mariotti SP, Pokharel G. Global magnitude of visual impairment caused by uncorrected refractive error in 2004. Bull World Health Org. 2008;86:63-70. http://dx.doi.org/10.2471/BLT.07.041210

20. World Health Organization. Global data on visual impairment: 2010 [cited 22 February 2013]. Available from: http/www.who.int/blindness/ GLOBALDATAFINALforweb.pdf

21. Oye JE, Kuper $H$, Dineen $B$, Befidi-Mengue $R$, Foster A. Prevalence and causes of blindness and visual impairment in Muyuka: A rural health district in South West Province, Cameroon. Br J Ophthalmol. 2006;90:538-542. http://dx.doi. org/10.1136/bjo.2005.082271

22. Abdull MM, Sivasupramanian S, Murthy GVS, et al. Causes of blindness and visual impairment in Nigeria. The National Blindness and Visual Impairment Survey. Invest Ophthalmol. 2009;50:4114-4120. http://dx.doi.org/10.1167/ iovs.09-3507
23. Holden BA, Resnikoff S. The role of optometry in Vision 2020. Comm Eye Health. 2002;15:33-36.

24. World Health Organization. Elimination of avoidable visual disability due to refractive errors. (WHO/PBL/00.79). Geneva: World Health Organization; 2000.

25. Naidoo K, Ravilla D. Delivering refractive error services: Primary eye care centers and outreach. Comm Eye J. 2007;20:42-43.

26. Index Mundi. Population-country comparison. [cited 22 February 2013]. Available from: http://www.indexmundi.com/g/r.aspx

27. Lecuona K. Analysis of eye care services in South Africa's public sector. Comm Eye Health. 2007;20:72.

28. Oduntan AO, Raliavhegwa $\mathrm{M}$. An evaluation of the impact of the eye care services delivered to the rural communities in the Mankweng health sub-district of the Northern Province. S Afr Optom. 2001;60:71-76.

29. Oduntan AO, Nthangeni ME, Ramudzuli R, Madu, SN. Causes and prevalence of low vision and blindness in the Limpopo Province of South Africa. S Afr Optom. 2003;62:8-15

30. Furdato IM, Lansingh VC, Winthrop KL, Sprivey B. Training of an ophthalmologist in concepts and practice of community eye health. Indian J Ophthalmol. 2012;60:365-367. http://dx.doi.org/10.4103/0301-4738.100528

31. Resnikoff S, Felch W, Gauthier TM, Spivey B. The number of ophthalmologists in practice and training worldwide: A growing gap despite more than 200, 000 practitioners. Br J Ophthalmol. 2012;96:783-787. http://dx.doi.org/10.1136/ bjophthalmol-2011-301378

32. Thivhafuni LG. Availability, accessibility and affordability of optometric services in the Mutale municipality, Vhembe District, Limpopo Province, South Africa [MPublHIth dissertation]. South Africa: University of Limpopo; 2011.

33. Reid SJ. Compulsory community service for doctors in South Africa: An evaluation of the year. S Afr Med J. 2001;91:329-336.

34. Naidoo K, Savage B, Westerfall B. Creating a sustainable spectacle delivery solution. Vision. 2006;15 July/August.

35. Jose R, Sachdeva S. School eye screening and the National Programme for Control of Blindness. Indian Pediatr. 2009;46:205-208.

36. Department of Basic Education, South Africa. Integrated School Health Policy, 2012. [cited 22 February 2013]. Available from: http://www.education.gov.za/ LinkClick.aspx?fileticket $=x 7$ XUJxMcfvs\%3D\&tabid $=870 \&$ mid $=2453$

37. Mashige KP, Martin C, Cassim B, Ramklass S, Esterhuizen TM. Utilization of eye care services by elderly persons in the northern Ethekwini district of KwaZuluNatal province, South Africa. S Afr Optom. 2011;70:175-181.

38. Ntsoane MD, Oduntan OA. A review of factors influencing the utilization of eye care services. S Afr Optom. 2010;69:182-192.

39. Bhagwan J, Rastogi I, Malik J, Dhull C. Knowledge, attitude and practices regarding cataract surgery among severe cataract cases in Hanyana. Indian J Com Med. 2006;31:66-68

40. Farmer J, Iversen L, Campbell NC, et al. Rural/urban differences in accounts of patients' initial decision to consult primary care. Health Place. 2006;12:210-221. $\mathrm{http}: / / \mathrm{dx}$.doi.org/10.1016/j.healthplace.2004.11.007

41. Nwosu SNN. Beliefs and attitude to eye diseases and blindness in Anambra State Nigeria. Nig J Ophthalmol. 2002;1:16-20. http://dx.doi.org/10.4314/njo.v10i1.11901

42. Patel D, Baker H, Murdoch I. Barriers to uptake of eye care services in the Indian population living in Ealing, London. Health Educ J. 2006;65:267-276. http:// dx.doi.org/10.1177/0017896906067777 